\title{
Review on Biogenic Synthesis of Nanoparticles and Their Therapeutic Applications: List of Novel Eco-Friendly Approaches
}

\author{
Harbans Kaur Kehri1 ${ }^{1}$ Ifra Zoomi¹, Uma Singh¹, Deepak Pandey², Dheeraj Pandey1,* \\ ${ }^{1}$ Sadasivan Mycopathology Laboratory, Department of Botany, University of Allahabad, Prayagraj - 211 002, Uttar Pradesh, India. \\ ${ }^{2}$ Mahamaya College of Agricultural Engineering and Technology, Akbarpur, Ambedkar Nagar - 224 142, Uttar Pradesh, India.
}

\section{A R T I C LEDETAILS}

\section{Article history:}

Received 22 May 2019

Accepted 09 June 2019

Available online 13 June 2019

Keywords:

Nanoparticles

Green Synthesized NPs

Phytoextract

\begin{abstract}
A B S T R A C T
Nano-technology is being frequently used in several aspect of life. Chemical and physical methods of nanoparticle synthesis generally involve high temperature, vacuum condition and harsh/toxic chemicals that cause adverse impact on environments including humans and are costly. Hence, there is a need of alternative method to synthesize nanoparticles. Biological approach that connects nanotechnology with plant extracts, fungi, honey etc. is the possible alternative of chemical and physical methods of nonparticles synthesis. Bio-tools are adapted in nano-biotechnology to promote the safer and sustainable application. This review focuses on the use of nano-catalysis and green chemistry for development of non-particles and their effective application in various biological and industrial, medical, agriculture etc.
\end{abstract}

\section{Introduction}

Nanomaterials are considered as the foundations of nanotechnology and Nano sciences. This technology is a wide-ranging and interdisciplinary sector of research development. In present scientific world nanotechnology used very frequently in major scientific and medical works. However, this technology emerged in the past few decades only but its history is traced in ancient India, Mesopotamia, and Rome civilization. The first Nobel Laureate "There are plenty of rooms at the bottom" on the concept of nanotechnology was delivered by Richard Feynman and term 'Nanotechnology' was first identified by Norio Taniguchi in 1974. Now-adays commercial use of nanoparticles in several industries such as electrical, chemical, biological, Robotics and textile industry. Nanomaterials have unique magnetic, electrical, optical and other properties. These emergent properties make them more suitable for great impacts in electronics, medicine, and other fields. These nanomaterials occur naturally such as fire smoke particles, seashells, skeletons, as well as by the particular interest it may designed called engineered nanomaterial. These engineered nanomaterials are used in cosmetics, stain-resistant clothing, tires, paints-varnishes, electronics and medicinal purposes such as disease diagnosis, imaging and targeted drug delivery. This nanophase engineering expanding rapidly with the composition, fusion of different materials and different phase of matrix materials.

Nanoparticles (NPs) are produced generally by physical and chemical methods. There are some common physical methods such as ion sputtering, thermal synthesis and by sol gel technique. Top down and bottom up method are applied to synthesize the nanomaterials commonly. In top down methods the bulk materials are broken down whereas in bottom up methods assemblies of atoms take place. Nanomaterial is characteristic in length; scale lies between one and few hundreds of nanometres (most preferably between 1-100 nm). Structure of Nanomaterial's is classified on the basis of dimension i.e. Zero dimensional, one dimensional (Graphene film), two dimensional (nanotubes of carbon) and three dimensional (quantum dots and Fullerene) [1]. However, on the basis of material composition nanoparticle can be inorganic, organic, or both (hybride), carbonaceous, liposomal with nanomaterial's and biological nanomaterials. Nanoparticles synthesized generally by chemical, physical methods. In chemical method capping agents are required for stabilization of size and this chemical reagent are toxic and leads to accumulation in environment. Humans are exposed to NPs in excess via air, food, water, as well as medical applications. Exposure of nanoparticles in air cause lung disease, oxidative stress, cancer and also adversely affects the immune system [2]. There are no safely disposal policies for NPs in the environment where their toxic effect is increasing, researches are needed to develop policies for nanoparticles disposal. So, there is a need of non-toxic and environmental-friendly approaches for NPs synthesis. Biological resources like bacteria, viruses, algae, fungi, plants, few enzymes, flavonoids, phenolics, terpenoids, cofactors etc. are being used in green synthesis of NPs.

\section{Green synthesis of Nanoparticles (NPs)}

Green synthesis adopts a bottom up approach in which extract of a natural product is used for synthesis of nanoparticles (Fig. 1). There is so much reduction of expensive chemical agents with many biological entities which produce eco-friendly, sustainable [3], free of toxic chemicals [3], cast effective and can be produce in huge quantity [5, 6]. Green NPs can be recycled and facilitate to reuse the expensive and limited metal salts. Mostly proteins, enzymes, sugars and even whole cells stabilize NPs during synthesis which increases other biomolecule interaction and also increases antimicrobial activity. It also gets separated easy from reaction media by centrifugation [7]. Green synthesized NPs pharmaceutical and nutraceutical properties enhancement depends on the bioresources. Moreover, it also depends on $\mathrm{pH}$, temperature, exposure time and salt concentration [8].

Desirable shape and sizes of NPs Single cell bacteria and extracts of multi-cellular eukaryotes in the reaction processes decreases metal precursors into newly synthesized NPs of desire sizes and shape [9]. However, applied bioagents/material act as growth terminator and inhibiting aggregation/agglomeration by capping and stabilizing agent during green synthesis [10]. Bio-reduction of nanomaterial production proceeds either in vitro or in vivo. In vivo methods are reported in green NPs synthesis by bacteria, fungi, yeast, algae and plants [10], however, bioextract assisted NPs synthesis mostly in vitro. Mostly microbes and plant extract are used for green NPs [11] and biogenic oxidation or reduction reactions are main step in obtaining uniform chemical composition of NPs mentioned in Figs. 1 and 2. 

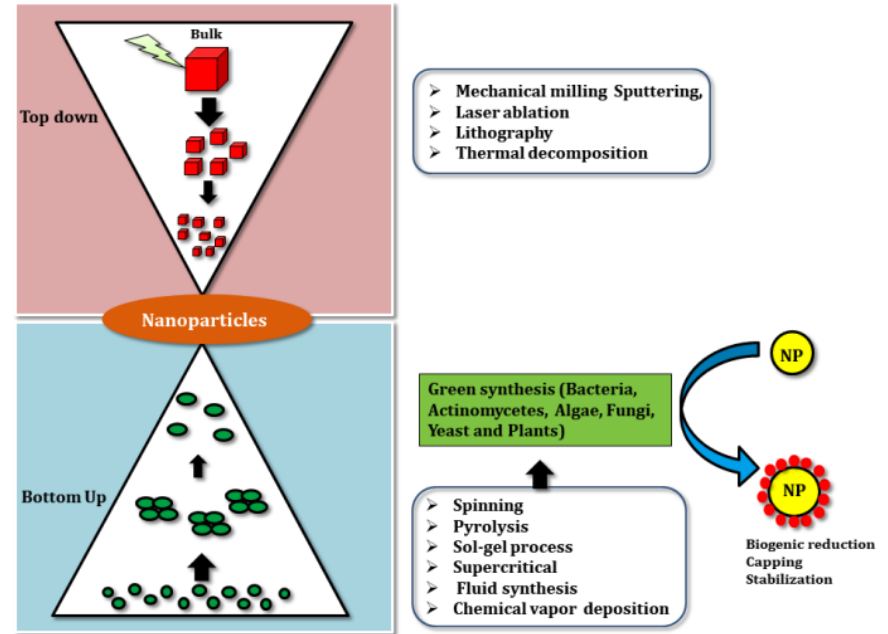

Fig. 1 Green synthesis of nanoparticles (an overview)

\subsection{Bacteria Mediated NPs Synthesis}

Bacteria are available globally as a cast effective and cheap source which is easy to manipulate temperature, $\mathrm{pH}$ and oxygenation for both types intracellular and extracellular synthesis of NPs. They produce lots of inorganic compounds extracellular. There is metal-microbe interaction present which provides potential for different bioremediation processes and also this potential utilized in bacterial mediated NPs synthesis [12]. The electrostatic attraction, presence of enzyme and negatively charged inner cell wall pay important role in intracellular NPs synthesis while enzyme mediated synthesis such as nitrate reductase or hydroquinone etc. in extracellular NPs synthesis [13]. In stress condition bacteria adopt several mechanisms to cope the adverse condition such as compartmentalization in vacuole, metal binding, efflux- influx of metallic ions, reduction, accumulation, transport, endocytosis, ion channels etc. Syneococcus sp. and Pseudomonas putida like some bacteria produce some cellular chemicals such as phytochelating peptides e.g. glutathione or cysteine rich protein Metallothioneines help in heavy metal detoxification [14-16] delftibactin a small non-ribosomal peptide in Delftia acidovorans which help producing the gold NPs. Bottom up extracellular synthesis of NPs is easy and can produce in rapid scale. Pseudomonas stutzeri AG259 isolated from the silver mines which produces Silver nanoparticles in the periplasmic space [17]. There are some other microbes related to silver NPs such as Bacillus amyloliquefaciens, Acinetobacter calcoaceticus, Escherichia coli, Bacillus megaterium $[18,19]$ Lactobacillus spp., Pediococcus pentosaceus, Enterococcus faecium and Lactococcus garvieae $[20,21]$ Rhodomonas capsulate, Delftia acidovorans can be excellent bioagents for gold NPs while some thermophilic bacteria associated with both gold and silver NPs $[15,16]$.

In Geobacter sp., Magnetospirillum magnetotacticumare Fe (III)reducing bacteria has an intracellular protein Ferritin help in producing NPs. $\mathrm{pH}$ of growth medium plays an important role and manipulation of different size and shape of NPs according to their applications [22]. He et al. saw NADH-dependant Reductase enzyme help the extracellular gold NPs production in Rhodopseudomonas capsulate [22]. Ordenes Aenishanslins et al. synthesized an important $\mathrm{TiO}_{2} \mathrm{NPs}$ through Bacillus mycoidesand $\mathrm{TiO}(\mathrm{OH})_{2}$ at $25{ }^{\circ} \mathrm{C}$ which presently used in green solar cells [23].

\subsection{Virus Mediated NPS}

Viruses are made up of non-segmented DNA or RNA and nucleoprotein. They replicate in living cell by utilizing the replication machinery of host cell. There are so many important features such as characteristic size, monodispersity and different chemical compounds present in virus which make them a potential for in assembling and producing nanoparticle assemblies e.g. tobacco mosaic virus (TMV) [24]. TMV virus also used as bio-template for several types of nanoparticles inside and outside the nanotubes. These nanocomposites are suitable for an engineering tools for smart nano-objects and nano-conjugates with noble metal nanoparticles e.g. cowpea mosaic virus (CPMV) [25]. Virus mediated nano-objects have ability to change in structure according to desire of need. Ling et al. found that M13 virus involved in metastable Fe face centered cubic to produce Uranium dioxide nanoparticles (crystals, 2-5 nm) [26].

\subsection{Actinomycetes Mediated NPS}

These are gram positive, branching filamentous bacteria. They have more resemblance with fungi so they are also called as "ray fungi". It can https://doi.org/10.30799/jnst.266.19050418 be easily modified genetically for production of NPs of different sizes [27]. They can produce antibiotics and this property can utilize in nanotechnology [28]. Streptomyces sp. VITSTK7, Rhodococcussp., Streptomyces albidoflavus, Streptomyces lomondensis etc. are actinomycetes which produced NPs extracellularly in different desirable size [29-32].

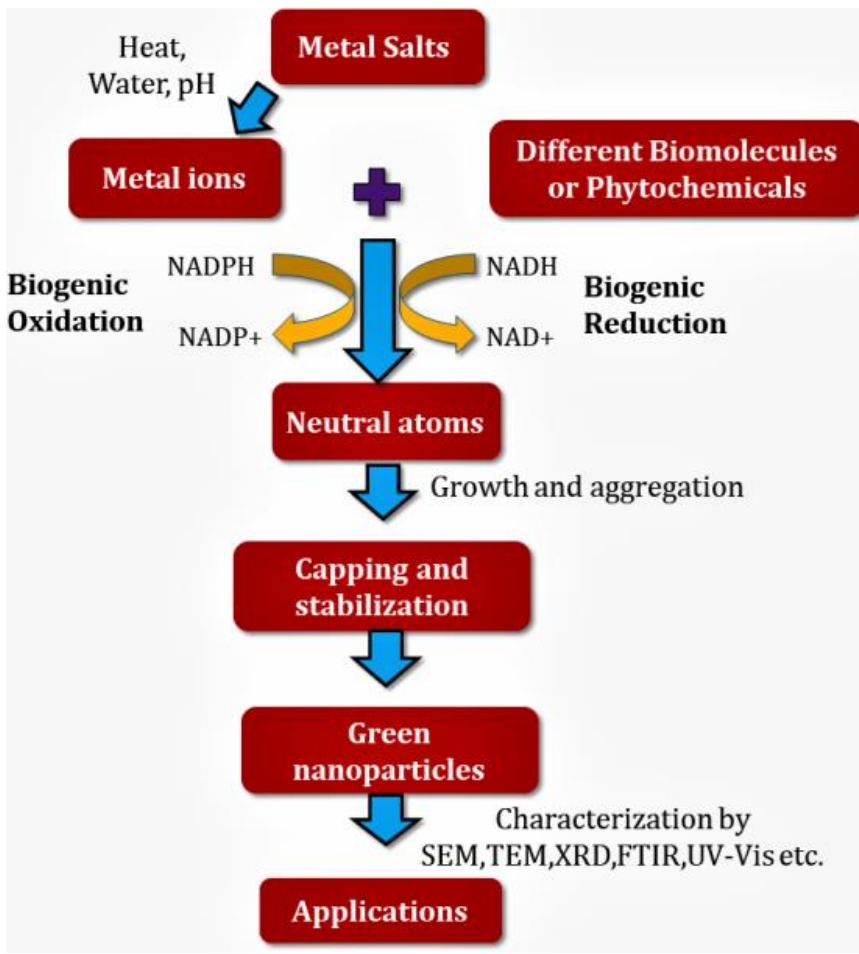

Fig. 2 Flow diagram of possible mechanism of green synthesis of nanoparticles

\subsection{Fungi Mediated NPS}

Use of fungi in green NPs synthesis is more suitable in comparison to bacteria. There is more surface area, secretion of more amounts of enzymes, secondary metabolites which accelerate the production of green NPs [33]. NADH-enzyme-mediated reducing reaction during gold NPs synthesis through Fusarium oxysporum. Fungal synthesize of NPs are more stable due to presence of cysteine and lysine residue in protein bonding. $F$. oxysporum can synthesize zirconia, silica, titania, cadmium sulphide (CdS), lead sulphide (PbS), zinc sulphide ( $\mathrm{ZnS})$, molybdenum sulphide (MoS) and $\mathrm{Au}-\mathrm{Ag}$ nanoparticles [34]. During the synthesis of silica and titania nanoparticles aqueous anionic complexes of Si and Ti, respectively $[35,36]$ while equimolar solution of $\mathrm{AuCl}_{4}$ and $\mathrm{AgNO}_{3}$ utilize in $\mathrm{Au}-\mathrm{Ag}$ NPs. Extracellular Silver NPs synthesis by Aspergillus fumigatus in the size range of 5-25 nm in very less time [36]. Trichoderma reesei also produce silver nanoparticles in size which ranges 5-50 nm but in comparison to $A$. fumigatus and F. oxysporum, it does not advantage over them [37]. Sanghi and Verma, investigated the silver NPs in white rot fungus Coriolus versicolor and found that this fungus can produce AgNPs by both conditional processes intracellularly and extracellularly [38]. Trichoderma asperellum and T. reeseiare commercially utilized in different sectors of pharmaceuticals, textile industries, food and paper industries. Verticillium sp. can synthesize AuNPs intracellulary [39]. Gold NPs are important in manufacture of electronic devices [40]. Langoria et al. synthesized Platinum NPs (PtNPs) by the use of Neurosporacrassa. These funguses synthesize PtNPs intracellularly whose size ranges from 4-35 nm in diameter [41]. F. oxysporumcan produces PtNPs both intracellularly and extracellularly but intracellularly production is less than extracellular however, temperature and $\mathrm{pH}$ influenced the NPs synthesis [42]. F. oxysporumand Verticillium sp. produced magnetite NPs (MaNPs) with the Magnetite $\left(\mathrm{Fe}_{3} \mathrm{O}_{4}\right)$ in growth medium [43]. Magnetite nanoparticles are important for magnetic resonance imaging, position sensing and magnetic recording devices in medical sector [44]. Aspergillus flavus work as the reducing and capping agent during $\mathrm{TiO}_{2}$ NPs synthesis and these green NPs showed potential antimicrobial activity against some infectious bacteria [45].

\subsection{Yeast Mediated NPS}

Yeast is eukaryotic, single cell fungus, traditionally utilized in fermentation and genetic biotechnology. Recent advancement makes their valuable application in nanotechnology. However, this field has to be 
explored. AuNPs were synthesized with the use of gold salt, Hansenula anomalaas bioreductant and polyamidoamine dendrimer as stabilizer [46, 47]. Pichia jadinii can produce triangular and hexagonal $(100 \mathrm{~nm})$ AuNPs in cytoplasm. In synthesis of semiconductors yeasts are applied. Torulopsis sp. produced CdS nanocrystallites intracellularly with spherical morphology and utilized to fabricate diode heterojunction [48]. Schizosaccharomyces pombe also produced CdS nonocrystallites intracellularly size ranges from 1-1.5 $\mathrm{nm}$ [49].

\subsection{Algae Mediated NPs}

Algae are cholrophyllous photosynthetic organisms present in different aquatic and muddy environment. Different types of algae developed different kinds of physiological and biochemical adaptation for their survival. This biochemical can be utilized for green NPs production. The synthesis of gold NPs through fucoidans a polysaccharide produced by marine brown algae. Brown algae have mucilaginous rich complex cell wall and presence of carboxyl groups facilitate the accumulation of heavy metals in the cell [50]. Algal bound AuNPs are produced in inner or outer cell wall with different shapes. Chlorella vulgaris is utilized as bioreducing agent in the synthesis of triangular and hexagonal AuNPs. There are some factors such as $\mathrm{pH}$, temperature and metallic ion concentration etc. greatly influence the size of newly synthesized NPs [51]. The anti-inflammatory, anti-viral, anti-coagulant and anti-cancer etc. properties of algae may be utilizing greatly through green NPs production commercially.

Table 1 Some examples of biosynthesized nanoparticles

\begin{tabular}{|c|c|c|c|c|}
\hline S.N. & Plant Used & Nanoparticle & Size $(\mathrm{nm}) /$ Shape & Ref. \\
\hline 1. & Agaricus bisporus & gold & 25 spherical & [109] \\
\hline 2. & Aloe vera & gold \& silver & spherical, triangular & [110] \\
\hline 3. & Andean blackberry & Silver & $12-50$ spherical & [111] \\
\hline 4. & Avena sativa & gold & $5-20$, rod-shaped & [112] \\
\hline 5. & Azadirachta indica & $\begin{array}{l}\text { gold, silver \& } \\
\text { silver-gold alloys }\end{array}$ & $\begin{array}{l}\text { 5-35 \& 50-100 spherical } \\
\text { triangular, hexagonal }\end{array}$ & [113] \\
\hline 6. & $\begin{array}{l}\text { Black tea leaf } \\
\text { extracts }\end{array}$ & gold \& silver & 20 spherical, prism & [114] \\
\hline 7. & Brassica juncea & silver & 2-35 spherical & [115] \\
\hline 8. & Camellia sinensis & gold & 40 spherical, triangular & [116] \\
\hline 9. & Carica papaya & silver & $60-80$ spherical & [117] \\
\hline 10. & Citrus limon & silver & $<50$ spherical spheroidal & [118] \\
\hline 11. & $\begin{array}{l}\text { Coriandrum } \\
\text { sativum, }\end{array}$ & gold & $\begin{array}{l}6.75-57.91 \text { spherical, } \\
\text { triangular decahedral }\end{array}$ & [119] \\
\hline 12. & $\begin{array}{l}\text { Eucalyptus } \\
\text { hybrida }\end{array}$ & silver & $\begin{array}{l}50-150 \text { crystalline, } \\
\text { spherical }\end{array}$ & [120] \\
\hline 13. & Ficus bengalensis & silver & $\sim 20$ spherical & [121] \\
\hline 14. & $\begin{array}{l}\text { Garcinia } \\
\text { mangostana }\end{array}$ & silver & 35 spherical & [122] \\
\hline 15. & Honey & silver & 4 spherical & [123] \\
\hline 16. & Hydrilla sp. & silver & $2-5$ fcc unit cell structure & [124] \\
\hline 17. & Medicago sativa & $\begin{array}{l}\text { titanium-nickel } \\
\text { alloys }\end{array}$ & $\begin{array}{l}\text { 1-4 fcc-like geometry for } \\
\text { smallest clusters }\end{array}$ & [125] \\
\hline 18. & Mentha piperita & silver & 90 spherical & [126] \\
\hline 19. & Musa paradisiaca & silver & crystalline, irregular & [127] \\
\hline 20. & Nelumbo nucifera & silver & $\begin{array}{l}25-80 \text { spherical, } \\
\text { triangular, decahedral }\end{array}$ & [128] \\
\hline 21. & $\begin{array}{l}\text { Ocimum sanctum } \\
\text { (tulsi; leaf extract) }\end{array}$ & gold & $\begin{array}{l}30 \text { crystalline, hexagonal, } \\
\text { triangular }\end{array}$ & [129] \\
\hline 22. & Olea europaea & Silver & 7-15 nm spherical & [130] \\
\hline 23. & $\begin{array}{l}\text { Pelargonium } \\
\text { graveolens }\end{array}$ & gold & $\begin{array}{l}\text { 20-40 decahedral, } \\
\text { icosahedral }\end{array}$ & [131] \\
\hline 24. & Pleurotus florida & Silver & $\begin{array}{l}2.445 \pm 1.08 \mathrm{~nm} \mathrm{fcc} \\
\text { crystalline }\end{array}$ & [132] \\
\hline 25. & Psidium guajava & gold & $25-30$ mostly spherical & [133] \\
\hline 26. & Syzygium cumini & silver & 29-92 spherical & [134] \\
\hline 27. & Tamarindus indica & gold & 20-40 triangular & [110] \\
\hline 28. & $\begin{array}{l}\text { Terminalia } \\
\text { catappa }\end{array}$ & gold & 10-35 spherical & [110] \\
\hline
\end{tabular}

\subsection{Plant Mediated NPs}

Plants show different adaptations according their habitat and environmental conditions. They produce lots of biomolecules such as enzymes, lipids, sugars, secondary metabolites etc. These important biochemicals are cheap and synthesized by the plants in large amount that facilitate the production of green metal NPs from their extract. Other biological sources for green synthesis of NPs such as bacteria, fungi and yeast required aseptic environments and are expensive therefore, not suitable for industrial production. There are so many ethnologically and biotechnologically important plants belonging to different phyla such Angiosperms, Gymnosperms, Pteridophytes, Bryophytes which may be https://doi.org/10.30799/jnst.266.19050418 utilized for production of NPs and these green NPs in various fields such as medical, pharmaceutical, cosmetics etc. Phytochemical mediated green NPs size and shape play a key role in biocompatibility [52-54]. However, biomedical applicable suitable size of green NPs is less than $100 \mathrm{~nm}$ [55]. There is no any authentic guideline for phytoextract mediated NPs synthesis; reaction temperature may vary according to metal of NPs. Raut et al. performed synthesis of green palladium (Pd) NPs in Asparagus racemosus with the help of sunlight [56]. Silver and gold NPs synthesis reported from various plants such as Tribulus terrestris, Rosmarinus officinalis, Sesbania grandiflora [57]. Azadirachta indica, Camellia sinensis, Aloe vera and Centella asiatica are important examples of medicinal plants that utilizes to produce green NPs. Leaf extract of Thuja orientalis act biogenic reductive during Au NPs synthesis at normal room temperature [58]. Similarly leaf extract of Ginkgo biloba act as reducing and stabilizing agent in copper NPs production at room temperature [59]. Torreya nucifera and Cycas circinalis leaf extract use in the synthesis of silver NPs size 10-25 and 13-51 nm respectively [60]. Velmurugan et al. reported involvement of phenolic compounds in silver NPs iin in Pinus thunbergii [60]. Phytochemical of Adiantum philippense might be involved in producing gold and silver NPs [62]. The brief details given in Table 1.

\section{Characterization of NPs}

Characterization is the determination of size, shape, homogeneity and other morphological characters of newly synthesized green NPs. There are so many common techniques which are utilizes for characterizing the NPs such as scanning electron microscopy (SEM), transmission electron microscopy (TEM), UV-Vis absorption spectroscopy, X-ray diffraction (XRD), infrared (FTIR) spectroscopy, dynamic light scattering (DLS), energy dispersive X-ray analysis (EDAX) etc. Advance microscopic techniques as atomic force microscopy (AFM), SEM, TEM help to determine the size, shape, morphology and surface charges of newly synthesized NPs. In aqueous suspension UV-Vis spectra were utilized to examine size and shape at 300 to $800 \mathrm{~nm}$ wavelength $[63,64]$. The DLS and EDAX also used in analysis of NPs size and its distribution in medium such as liquid and the solid elemental medium respectively [65]. XRD technique utilized $\mathrm{X}$-rays penetration to investigate the metallic translational symmetry, size and phase of metallic NPs. This X-rays penetration gives diffraction pattern and by comparison these peaks to standard peaks determine the above information. FTIR spectroscopy can determine the functional group identification of stabilizing or reduction agent of green rout NPs synthesis.

\section{Application of Green Synthesized NPs}

In present scientific scenario the use of NPs enhanced very much. The green NPs are the sustainable approaches which transform its potential application in diverse fields such as cosmetics, pharmaceuticals, medical and other industries. These green NPs are very much facilitating to diverse their roles in clinical application such as antibacterial effects, antifungal effects, anti-parasitic activity and in vitro diagnosis of disease [66]. These Green NPs may be utilized as potential tools to disinfection of surface, ground water from pollutant and infectious microorganisms [67]. Silver as disinfectant is utilized commercially in water purifiers. Xie et al. investigate the possible role of magnetotactic bacteria (MTB) NPs in medical field and found their role for gene transfer and PEI-associated MTB-NPs to deliver b-galactosidase plasmids both in vitro and in vivo conditions [68]. Application of photostable fluorescent NPs in tracking the delivery of nucleic acid, the grade of transfection in cells and in purifying evenly silenced sub populations $[69,70]$. NPs are eco-friendly replacements of pesticides and also act as effective fertilizers increasing crop production $[71,72]$.

\subsection{Antibacterial}

In present days the problem of antibiotic resistance is gradually increasing in the microbes and many antibacterial medicines and drugs are becoming less effective. There is a new emphasis with use of silver NPs based antiseptics utilized for better results. Different bioagents with antimicrobial properties are applied for biosynthesis of silver-based NPs. Fayaz et al. biosynthesized the silver NPs with the help of Trichoderma viride and size ranges $5-40 \mathrm{~nm}$. These antiseptics were tested with some Gram-positive and Gram-negative bacteria and found their amalgamation with ampicillin, kanamycin, erythromycin, and which chloramphenicol give better results in comparison to solo antibiotic application [72]. Bindhu and Umadevi prepared the Silver NPs with beetroot extract and found its potential role in inhibiting the growth of both Gram positive and Gram-negative bacteria [73]. Leaf extract of Anogeissus acuminate was 
used in synthesis of silver NPs and the size was below $100 \mathrm{~nm}$. It could control most MDR UTI bacteria [74]. Patra and Beak prepared silver NPs with the application of waste of Zea mays and found their potential role against many feet borne bacteria [75].

\subsection{Antifungal}

There are many silver/gold based green NPs which have been studied they show the potential role in antifungal activity. Fungus mediated silver NPs with combination of fluconazole shows antifungal activities against Phoma glomerata, P. herbarum, Fusarium semitectum, Trichoderma sp. and Candida albicans [76]. Banker et al. synthesized banana peel extract based gold NPs that prevent the growth of Candida albicans [77]. Rhizopus oryzae mediated gold NPs inhibit the growth of C. albicans, Saccharomyces cerevisiae and also showed inhibition of Gram positive and Gram-negative bacteria [78]. Mallmann et al. synthesized silver NPs using biomolecules such as ribose and sodium dodecyl sulfate (SDS) and evaluated its antifungal activity against $C$. albicans and $C$. tropicalis [79]. Khatami et al. utilized dried leaf extract in the green synthesis of silver NPs and found highest inhibitory effect on Fusarium solani at $20 \mu \mathrm{g} / \mathrm{mL}$ of AgNPs and 5 $\mu \mathrm{g} / \mathrm{mL}$ AgNPs inhibit the cancer cell growth [80]. Xue et al. reported a residue-free green NPs of Zinc oxide- thiram antifungal composition which follows photocatatytic degradation which prevents negative effect of pesticide on environment [81].

\subsection{Antiviral}

De Gusseme et al. reported the potential use of green Ag NPs in the virus free drinking water [82]. Specific interaction of 1-100 nm silver NPs with HIV-1 virus control the HIV infection by binding of NPs on gp 120 glycoprotein knobs [83, 84]. There are some other metallic NPs synthesized which inhibited the virus infection. Lysenko et al. studied two types of gold NPs with $\mathrm{SiO}_{2}$ shell against the adenoviruses and found them both are effective [85]. Gaikwad et al. investigated the antiviral activity of silver NPs against the herpes simplex virus 1 and 2 and with Para influenza virus 3 and concluded that smaller sized NPs are able to prevent the virus infection intensity by blocking interaction of the virus with the cell [86]. Mori et al. also found same type of results with silver NPs against H1N1 influenza [87].

\subsection{Catalytic Activity}

The catalytic activity of green NPs is dependent on their size, energy and surface area [88]. The different plant mediated silver NPs showed their catalytic reduction activity on different chemical compounds such as sodium borohydride, benzyl chloride, hydrogen peroxide etc. Ulva lactuca mediated silver NPs photocatalytic degraded the methyl orange and Gloriosa superba mediated AgNPs degraded the methylene blue [89]. Catalytic reduction of hydrogen peroxide has been reported by the Triticum aestivum mediated silver NPs [90]. Muthu and Priya synthesized silver NPs by Cassia auriculata which reduced the 4-nitrophenol and methyl orange [91].

\subsection{Anti-Cancer Activity}

Free radicles are toxic by-products of aerobic metabolism. They are primarily or secondarily synthesized at different sites of the cell and can damage the biomolecules, nucleic acid and cell components which lead the cell death. Application of silver NPs accelerates cell apoptosis through the induction of $\mathrm{P}^{53}$ mediated apoptosis [89]. Jacob et al. synthesized Piper longum mediated silver NPs which show cytotoxic effect on HEp-2 cancer cell line and dose dependent cytotoxic effect of green silver NPs on HT 29 cancer cells [92, 93]. Kummara et al. biosynthesized silver NPs with Azadirachta indica and tested against human skin dermal fibroblast (HDFa) and anticancer activity in NCI-H460 cells. Significant cytotoxic effect was found and induced apoptosis in NCI-H460 cells but no significant result in case of human skin dermal fibroblast (HDFa) [94]. Rajesh Kumar synthesized gold NPs with Enterococcus sp. and NPs shows significant anticancer activity against the HepG2 and A549 cell lines at 100 $\mu \mathrm{g}$ concentration [95].

\subsection{Biosensor}

The adherence of different biomolecules on NPs make them enables to act as indicator which can be detected by absorption and scatting spectrum and Optical and electronic features of different NPs are potentially utilized as biosensor and applied as specific indicator in such fields like medical application and research. There are so many gold and silver alloy NPs which were utilized as electronically chemical vanillin sensors [96]. Silver NPs (cubical and rhombohedral) are utilized to biosensing of protein interaction [97]. Haes et al. utilized NPs biosensor for two biomolecule detection in Alzheimer's disease [98]. These silver https://doi.org/10.30799/jnst.266.19050418
NPs probes are utilized fordiagnostic detection in Prostate specific Antigen (PSA) for the confirmation of sperm status in adult [99].

\subsection{Bioimaging}

Commonly florescent chemical dyes were used for the imaging the biological objects under the optical microscopy techniques. Now-a-days photoluminescence features, photostability, plasmonic properties of NPs are well utilized for imaging of such objects. Sarkar et al. investigated Trichoderma viride mediated silver NPs for imaging and labeling [100] The synthesis of cadmium telluride quantum dots (CdTe QDs) are extracellularly mediated with Saccharomyces cerevisiae [101] and Escherichia coli and with the folic acid these dots are applied in imaging of cancer cells in vitro condition [102]. Lee et al. studied the early embryonic development in zebra fish and demonstrated their stages through silver NPs [103].

\subsection{Medical tools}

\subsubsection{Catheters}

The flexible plastic narrow tubes are employed for removing fluids like blood, urine and bio wastes through narrow opening. There is need of thin, flexible and non-infectious material for catheters so silver NPs are utilized as a bioactive coating material on narrow tube. It reduces the infection chances because of antimicrobial activity. Bio coated engineered gold NPs are also used in catheters [104]. These NPs prevent the bacterial biofilm formation on catheters surface by altering the cell membrane integrity and proliferation and interferes in respiratory and enzymatic activity [105].

\subsubsection{Bone Cementing Material}

Bone cements are commonly poly methyl methacrylate (PMMA) which are synthetic materials used to fill the bone gaps, anchor artificial joints etc. Green synthesized silver NPs provide the flexible antimicrobial and low cytotoxicity material [106]. Prokopovich et al. synthesized oleic acid capped silver NPs which are incorporated in bone cement at various ratio and it showed the antimicrobial activity against Staphylococcus aureus, Staphylococcus epidermidis, Acinetobacter baumannii at low concentration also [107]. Gold NPs in PMMA material with specific concentration improved the punching performance and antibacterial activity [108]. In modern era antimicrobial properties of green NPs are utilized in wound dressing creams, dental implant materials, contact lenses, heart valve, pacemaker, endotracheal tubes etc.

\section{Conclusion}

Nanotechnology is an emerging discipline of applied science. The potential researches are now proved its multidisciplinary importance in various fields of science and daily life. Nanoscience has brought the manufacturing research at Nano level modifications in their structure and properties that changed the idea and horizon of industry and research. Various metallic compounds used in the synthesis of nanoparticles. These heavy metals are discharged in open system or in biological system. There is a risk of environmental toxicity and biomagnifications. So, the recent researches utilize biological resources for green synthesis of nanoparticles by the application of many microbes, plants parts and biomolecules etc. Biosynthesis of nanoparticles with the application of biological material enhanced the properties of nanoparticles which facilitate the multidisciplinary application. This is environmentally friendly and sustainable approach in the field of nanotechnology.

\section{Acknowledgement}

The authors are thankful to University Grant Commission (UGC), New Delhi and Head of Botany Department of University of Allahabad, Allahabad, India for providing financial assistance and library facilities. Dheeraj Pandey also thankful to Raghvendra P. Narayan, Department of Botany, NSCBGG PG College, Lucknow and Vivek K. Chaturvedi, Department of Biotechnology, University of Allahabad for his valuable suggestion during manuscript preparation.

\section{References}

[1] R.W. Siegel, Characterization of nanoparticles and nanophase materials, Argonne National Lab, IL, United States, 1994

[2] R.D. Handy, B.J. Shaw, Toxic effects of nanoparticles and nanomaterials, implications for public health, risk assessment and the public perception of nanotechnology. Health Risk Soc. 9 (2007) 125-44. 
[3] M. Gopinath, R. Subbaiya, M.M. Selvam, D. Suresh, Synthesis of copper nanoparticles from Nerium oleander leaf aqueous extract and its antibacterial activity, Int. J. Curr. Microbiol. App. Sci. 3 (2014) 814-818.

[4] X. Huang, P.K. Jain, I.H. El-Sayed, M.A. El-Sayed, Gold nanoparticles, interesting optical properties and recent applications in cancer diagnostics and therapy, Nanomedicine (Lond.) 2(5) (2007) 681-693

[5] A.K. Mittal, Y. Chisti, U.C. Banerjee, Synthesis of metallic nanoparticles using plant extracts, Biotechnol Adv. 31 (2013) 346-56.

[6] S. Iravani, Green synthesis of metal nanoparticles using plants, Green Chem. 13 (2011) 2638-2650.

[7] L. Sintubin, W. De Windt, J. Dick, J. Mast, Ha D. Van Der, W. Verstraete, N. Boon, Lactic acid bacteria as reducing and capping agent for the fast and efficient production of silver nanoparticles, Appl. Microbiol Biotechnol. 84 (2009) 741749.

[8] M. Gericke, A. Pinches, Biological synthesis of metal nanoparticles, Hydromet. 83 (2006) 132-40.

[9] A. Kaushik, M. Singh, G. Verma, Green nanocomposites based on thermoplastic starch and steam exploded cellulose nanofibrils from wheat straw, Carbohydr. Polym. 82 (2010) 337-45.

[10] O.V. Kharissova, H.R. Dias, B.I. Kharisov, B.O. Pérez, V.M. Pérez, The greener synthesis of nanoparticles, Trends Biotechnol. 31 (2013) 240-248.

[11] S. Joglekar, K. Kodam, M. Dhaygude, M. Hudlikar, Novel route for rapid biosynthesis of lead nanoparticles using aqueous extract of Jatropha curcas L. latex, Mater. Lett. 65 (2011) 3170-3172.

[12] M.I. Husseiny, M.A. El-Aziz, Y. Badr, M.A. Mahmoud, Biosynthesis of gold nanoparticles using Pseudomonas aeruginosa, Spectrochim. Acta A Mol. Biomol. Spectrosc. 67 (2007) 1003-1006.

[13] R.S. Soumya, S. Ghosh, E.T. Abraham, Preparation and characterization of guar gum nanoparticles, Int. J. Biol. Macromol. 46 (2010) 267-269.

[14] C. Xu, X. Qu, Cerium oxide nanoparticle, a remarkably versatile rare earth nanomaterial for biological applications, NPG Asia Mater. 6 (2014) e90:1-16.

[15] M. Gomathy, K.G. Sabarinathan, Microbial mechanisms of heavy metal tolerance-a review, Agricult. Rev. 31(2) (2010) 133-138.

[16] C.W. Johnston, M.A. Wyatt, X. Li, A. Ibrahim, J. Shuster, G. Southam, N.A. Magarvey, Gold biomineralization by a metallophore from a gold-associated microbe, Nat. Chem. Biol. 9(4) (2013) 241-243.

[17] T. Klaus, R. Joerger, E. Olsson, C.G. Granqvist, Silver-based crystalline nanoparticles, microbially fabricated, Proc. Natl. Acad. Sci. USA 96 (1999) 13611-13614.

[18] A.S. Reddy, C.Y. Chen, C.C. Chen, J.S. Jean, H.R. Chen, et al., Biological synthesis of gold and silver nanoparticles mediated by the bacteria Bacillus subtilis, J. Nanosci. Nanotechnol. 10 (2010) 6567-6574.

[19] X. Wei, M. Luo, W. Li, L. Yang, X. Liang, et al., Synthesis of silver nanoparticles by solar irradiation of cell-free Bacillus amyloliquefaciens extracts and $\mathrm{AgNO}_{3}$, Bioresour. Technol. 103 (2012) 273-278.

[20] V.L. Das, R. Thomas, R.T. Varghese, E.V. Soniya, J. Mathew, E.K. Radhakrishnan, Extracellular synthesis of silver nanoparticles by the Bacillus strain CS 11 isolated from industrialized area, Biotech. 4 (2014) 121-126.

[21] S. Denisa, J. Poř́źka, P. Kulich, A. Španová, P. Diviš, B. Rittich. Silver nanoparticles production with probiotic bacteria, Int. Mater. Sci. Forum. 851 (2016) 32-36.

[22] S. He, Z. Guo, Y. Zhang, S. Zhang, J. Wang, N. Gu, Biosynthesis of gold nanoparticles using the bacteria Rhodopseudomonas capsulate, Mater. Lett. 61 (2007) 3984-3987.

[23] N.A. Órdenes-Aenishanslins, L.A. Saona, V.M. Durán-Toro, J.P. Monrás, D.M. Bravo, J.M. Pérez-Donoso, Use of titanium dioxide nanoparticles biosynthesized by Bacillus mycoides in quantum dot sensitized solar cells, Microb. Cell Fact. 13(90) (2014) 1-10.

[24] P. Velusamy, G.V. Kumar, V. Jeyanthi, J. Das, R. Pachaiappan, Bio-inspired green nanoparticles, synthesis, mechanism, and antibacterial application, Toxicol. Res. 32(2) (2016) 95-102

[25] A.S. Blum, C.M. Soto, C.D. Wilson, T.L. Brower, S.K. Pollack, et al., An engineered virus as a scaffold for three-dimensional self-assembly on the nanoscale. Small 1 (2005) 702-706.

[26] T. Ling, H. Yu, Z. Shen, H. Wang, J. Zhu, Virus-mediated FCC iron nanoparticle induced synthesis of uranium dioxide nanocrystals, Nanotechnol. 19 (2008) 1156-1108.

[27] A. Ahmad, P. Mukherjee, S. Senapati, D. Mandal, M.I. Khan, R. Kumar, M. Sastry, Extracellular biosynthesis of silver nanoparticles using the fungus Fusarium oxysporum, Colloids Surf. B Biointerf. 28 (2003) 313-318.

[28] X. Zhang, S. Yan, R.D. Tyagi, R.Y. Surampalli, Synthesis of nanoparticles by microorganisms and their application in enhancing microbiological reaction rates, Chemosphere 82 (2011) 489-494.

[29] M. Thenmozhi, K. Kannabiran, R. Kumar, V.G. Khanna, Antifungal activity of Streptomyces sp. VITSTK7 and its synthesized Ag20/Ag nanoparticles against medically important Aspergillus pathogens, J. Med. Mycol. 23 (2013) 97-103.

[30] S.V. Otari, R.M. Patil, N.H. Nadaf, S.J. Ghosh, S.H. Pawar, Green biosynthesis of silver nanoparticles from an actinobacteria Rhodococcus sp., Mater. Lett. 72 (2012) 92-94.

[31] R.S. Prakasham, S.K. Buddana, S.K. Yannam, G.S. Guntuku, Characterization of silver nanoparticles synthesized by using marine isolate Streptomyces albidoflavus, J. Microbiol. Biotechnol. 22 (2012) 614-621.

[32] M.K. Sukanya, K.A. Saju, P.K. Praseetha, G. Sakthivel, Therapeutic potential of biologically reduced silver nanoparticles from actinomycete cultures, J. Nanosci. 2013 (2013) 940719:1-8.

[33] P. Mukherjee, A. Ahmad, D. Mandal, S. Senapati, S.R. Sainkar, et al., Fungusmediated synthesis of silver nanoparticles and their immobilization in the mycelial matrix, a novel biological approach to nanoparticle synthesis, Nano Lett. 1 (2001) 515-519.

[34] A. Ahmad, P. Mukherjee, D. Mandal, S. Senapati, M.I. Khan, et al., Enzyme mediated extracellular synthesis of CdS nanoparticles by the fungus, Fusarium oxysporum, J. Am. Chem. Soc. 124 (2002) 12108-12109

[35] V. Bansal, A. Ahmad, M. Sastry, Fungus-mediated biotransformation of amorphous silica in rice husk to nanocrystalline silica, J. Am. Chem. Soc. 128 (2006) 14059-14066.

[36] K.C. Bhainsa, S.F. D'souza, Extracellular biosynthesis of silver nanoparticles using the fungus Aspergillus fumigatus, Colloids Surf. B Biointerf. 47 (2006) 160-164.

[37] K. Vahabi, G.A. Mansoori, S. Karimi, Biosynthesis of silver nanoparticles by fungus Trichoderma reesei (a route for large-scale production of AgNPs, Insci. J. 1 (2011) 65-79.

[38] R. Sanghi, P. Verma, A facile green extracellular biosynthesis of CdS nanoparticles by immobilized fungus, Chem. Eng. J. 155 (2009) 886-891.

[39] S.M. El-Sonbaty, Fungus-mediated synthesis of silver nanoparticles and evaluation of antitumor activity, Cancer Nanotechnol. 4(4-5) (2013) 73-79.

[40] S. Eustis, M.A. El-Sayed, Why gold nanoparticles are more precious than pretty gold, noble metal surface plasmon resonance and its enhancement of the radiative and nonradiative properties of nanocrystals of different shapes, Chem. Soc. Rev. 35 (2006) 209-217.

[41] E.C. Longoria, S.M. Velasquez, A.V. Nestor, E.A. Berumen, M.A. Borja, Production of platinum nanoparticles and nanoaggregates using Neurospora crassa, J. Microbiol. Biotechnol. Res. 22 (2012) 1000-1004.

[42] T.L. Riddin, M. Gericke, C.G. Whiteley, Analysis of the inter and extracellular formation of platinum nanoparticles by Fusarium oxysporum F. sp. lycopersici using response surface methodology, Nanotech. 17 (2006) 34-82.

[43] A. Bharde, D. Rautaray, V. Bansal, A. Ahmad, I. Sarkar, et al., Extracellular biosynthesis of magnetite using fungi, Small 2 (2006) 135-141.

[44] D. Thapa, V.R. Palkar, M.B. Kurup, S.K. Malik, Properties of magnetite nanoparticles synthesized through a novel chemical route, Mater. Lett. 58 (2004) 2692-2694.

[45] G. Rajakumar, A.A. Rahuman, S.M. Roopan, V.G. Khanna, G. Elango, et al., Fungus-mediated biosynthesis and characterization of $\mathrm{TiO}_{2}$ nanoparticles and their activity against pathogenic bacteria, Spectrochim. Acta A Mol. Biomol. Spectrosc. 91 (2012) 23-29.

[46] A. Kumar, A.K. Pandey, S.S. Singh, R. Shanker, A. Dhawan, Engineered ZnO and $\mathrm{TiO}_{2}$ nanoparticles induce oxidative stress and DNA damage leading to reduced viability of Escherichia coli, Free Radic. Biol. Med. 51 (2011) 1872-1881.

[47] V.K. Chaturvedi, A. Singh, S.K. Dubey, H.F. Hetta, J. John, M.P. Singh, Molecular mechanistic insight of hepatitis B virus mediated hepatocellular carcinoma, Microb. Pathog. 128 (2019) 184-194.

[48] M. Kowshik, S. Ashtaputre, S. Kharrazi, W. Vogel, J. Urban, S.K. Kulkarni, K.M Paknikar, Extracellular synthesis of silver nanoparticles by a silver-tolerant yeast strain MKY3, Nanotech. 14 (2002) 95-ENDPAGE.

[49] C. Mao, C.E. Flynn, A. Hayhurst, R. Sweeney, J. Qi, et al., Viral assembly of oriented quantum dot nanowires, Proc. Natl. Acad. Sci. 100 (2003) 6946-6951.

[50] J. Venkatesan, P. Manivasagan, S.K. Kim, A.V. Kirthi, S. Marimuthu, A.A. Rahuman, Marine algae-mediated synthesis of gold nanoparticles using a novel Ecklonia cava, Bioprocess Biosyst. Eng. 37 (2014) 1591-1597.

[51] J. Xie, J.Y. Lee, D.I. Wang, Y.P. Ting, Identification of active biomolecules in the high-yield synthesis of single-crystalline gold nanoplates in algal solutions, Small 3 (2007) 672-682.

[52] H.K. Patra, S. Banerjee, U. Chaudhuri, P. Lahiri, A.K. Dasgupta, Cell selective response to gold nanoparticles, Nanomed. 3 (2007) 111-119.

[53] N. Lewinski, V. Colvin, R. Drezek, Cytotoxicity of nanoparticles, small. 4 (2008) 26-49.

[54] A.M. Alkilany, C.J. Murphy, Toxicity and cellular uptake of gold nanoparticles, what we have learned so far?, J Nanopart. Res. 12 (2010) 2313-2333.

[55] J. Das, P. Velusamy, Antibacterial effects of biosynthesized silver nanoparticles using aqueous leaf extract of Rosmarinus officinalis L, Mater. Res. Bull. 48 (2013) 4531-4537.

[56] R.W. Raut, A.S. Haroon, Y.S. Malghe, B.T. Nikam, S.B. Kashid, Rapid biosynthesis of platinum and palladium metal nanoparticles using root extract of Asparagus racemosus Linn, Adv. Mat. Lett. 4 (2013) 650-654.

[57] T. Das, S. Sehar, M. Manefield, The roles of extracellular DNA in the structural integrity of extracellular polymeric substance and bacterial biofilm development,Environ. Microbiol. Rep. 5 (2013) 778-786.

[58] M. Noruzi, D. Zare, D. Davoodi, A rapid biosynthesis route for the preparation of gold nanoparticles by aqueous extract of cypress leaves at room temperature, Spectrochim. Acta A Mol. Biomol. Spectrosc. 94 (2012) 84-88.

[59] M. Nasrollahzadeh, S.M. Sajadi, Green synthesis of copper nanoparticles using Ginkgo biloba L. leaf extract and their catalytic activity for the Huisgen [3+2] cycloaddition of azides and alkynes at room temperature, J. Colloid Interf. Sci. 457 (2015) 141-147.

[60] I. Johnson, H.J. Prabu, Green synthesis and characterization of silver nanoparticles by leaf extracts of Cycas circinalis, Ficus amplissima, Commelina benghalensis and Lippia nodiflora, Int. Nano Lett. 5 (2015) 43-51.

[61] P. Velmurugan, S.M. Lee, M. Iydroose, K.J. Lee, B.T. Oh, Pine cone-mediated green synthesis of silver nanoparticles and their antibacterial activity against agricultural pathogens, Appl. Microbiol. Biotechnol. 97 (2013) 361-368.

[62] D.G. Sant, T.R. Gujarathi, S.R. Harne, S. Ghosh, R. Kitture, et al., Adiantum philippense $\mathrm{L}$. frond assisted rapid green synthesis of gold and silver nanoparticles, J. Nanomater. 2013 (2013) 182320:1-9.

[63] W. Raut Rajesh, R. Jaya Lakkakula, S. Niranjan Kolekar, D. Vijay Mendhulkar, B. Sahebrao Kashid, Phytosynthesis of silver nanoparticle using Gliricidia sepium (Jacq.), Curr. Nanosci. 5 (2009) 117-122.

[64] B.K. Teo, H. Zhang, D.L. Feldheim, C.A. Jr Foss, Metal nanoparticles synthesis, characterization, and application, Marcel Dekker, New York, 2002.

[65] J. Jiang, G. Oberdörster, P. Biswas, Characterization of size, surface charge, and agglomeration state of nanoparticle dispersions for toxicological studies, J. Nanopart. Res. 11 (2009) 77-89. 
[66] A. Arumugam, C. Karthikeyan, A.S. Hameed, K. Gopinath, S. Gowri, V. Karthika, Synthesis of cerium oxide nanoparticles using Gloriosa superba L. leaf extract and their structural, optical and antibacterial properties, Mater. Sci. Eng. C Struct. Mater. 49 (2015) 408-415.

[67] P. Dhandapani, S. Maruthamuthu, G. Rajagopal, Bio-mediated synthesis of $\mathrm{TiO}_{2}$ nanoparticles and its photocatalytic effect on aquatic biofilm, J. Photochem. Photobiol. B Biol. 110 (2012) 43-49.

[68] J. Xie, K. Chen, X. Chen, Production, modification and bio-applications of magnetic nanoparticles gestated by magnetotactic bacteria, Nano Res. 2 (2009) 261-278.

[69] Z. Chen, H. Meng, G. Xing, C. Chen, Y. Zhao, et al., Acute toxicological effects of copper nanoparticles in vivo, Toxicol. Lett. 163 (2006) 109-120.

[70] V.K. Chaturvedi, S. Agarwal, K.K. Gupta, P.W. Ramteke, M.P. Singh, Medicinal mushroom: boon for therapeutic applications, Biotech. 8 (2018) 1-20.

[71] L.R. Khot, S. Sankaran, J.M. Maja, R. Ehsani, E.W. Schuster, Applications of nanomaterials in agricultural production and crop protection, a review, Crop. Prot. 35 (2012) 64-70.

[72] A.M. Fayaz, K. Balaji, M. Girilal, R. Yadav, P.T. Kalaichelvan, R. Venketesan, Biogenic synthesis of silver nanoparticles and their synergistic effect with antibiotics, a study against gram-positive and gram-negative bacteria, Nanomed. 6 (2010) 103-109.

[73] M.R. Bindhu, M. Umadevi, Antibacterial and catalytic activities of green synthesized silver nanoparticles, Spectrochim. Acta A Mol. Biomol. Spectrosc. 135 (2015) 373-378.

[74] M.P. Mishra, R.N. Padhy, Antibacterial activity of green silver nanoparticles synthesized from Anogeissus acuminata against multidrug resistant urinary tract infecting bacteria in vitro and host-toxicity testing, J. App. Biomed. 16 (2018) 120-125.

[75] J.K. Patra, K.H. Baek, Antibacterial activity and synergistic antibacterial potential of biosynthesized silver nanoparticles against foodborne pathogenic bacteria along with its anticandidal and antioxidant effects, Front Microbiol. 8 (2017) 167:1-14

[76] M. Gajbhiye, J. Kesharwani, A. Ingle, A. Gade, M. Rai, Fungus-mediated synthesis of silver nanoparticles and their activity against pathogenic fungi in combination with fluconazole, Nanomed. NBM. 5 (2009) 382-386.

[77] A. Bankar, B. Joshi, A.R. Kumar, S. Zinjarde, Banana peel extract mediated novel route for the synthesis of silver nanoparticles, Colloids Surf. A Physicochem. Eng. Asp. 368 (2010) 58-63.

[78] S.K. Das, A.R. Das, A.K. Guha, Gold nanoparticles, microbial synthesis and application in water hygiene management, Langmuir 25 (2009) 8192-8199.

[79] E.J. Mallmann, F.A. Cunha, B.N. Castro, A.M. Maciel, E.A. Menezes, P.B. Fechine, Antifungal activity of silver nanoparticles obtained by green synthesis, Rev. Inst. Med. Trop. Sao. Paulo. 57 (2015) 165-167.

[80] M. Khatami, H. Alijani, M. Nejad, R. Varma, Core@ shell nanoparticles, greener synthesis using natural plant products, App Sci. 8 (2018) 411:1-17.

[81] J. Xue, Z. Luo, P. Li, Y. Ding, Y. Cui, Q. Wu, A residue-free green synergistic antifungal nanotechnology for pesticide thiram by ZnO nanoparticles, Sci. Rep. 4 (2014) 5408:1-9.

[82] B. De Gusseme, L. Sintubin, L. Baert, E. Thibo, T. Hennebel, et al., Biogenic silver for disinfection of water contaminated with viruses, Appl. Environ. Microbiol. 76 (2010) 1082-1087

[83] J.L. Elechiguerra, J.L. Burt, J.R. Morones, A. Camacho-Bragado, X. Gao, et al., Interaction of silver nanoparticles with HIV-1, J. Nanobiotech. 3(6) (2005) 110 .

[84] H.H. Lara, N.V. Ayala-Nuñez, L. Ixtepan-Turrent, C. Rodriguez-Padilla, Mode of antiviral action of silver nanoparticles against HIV-1, J. Nanobiotech. 8(1) (2010) 1-7.

[85] V. Lozovski, N. Rusinchuk, V. Lysenko, M. Lokshyn, Y. Gomeniuk, et al., Nearfield aspects of antiviral action of complex nanoparticles on adenovirus, In 2018 IEEE 38th Int. Conf. Electron. Nanotech. (ELNANO) 24 (2018) 331-334.

[86] S. Gaikwad, A. Ingle, A. Gade, M. Rai, A. Falanga, et al., Antiviral activity of mycosynthesized silver nanoparticles against herpes simplex virus and human parainfluenza virus type 3, Int. J. Nanomed. 8 (2013) 4303-4314.

[87] Y. Mori, T. Ono, Y. Miyahira, V.Q. Nguyen, T. Matsui, M. Ishihara, Antiviral activity of silver nanoparticle/chitosan composites against H1N1 influenza A virus, Nanoscale Res. Lett. 8 (2013) 93:1-6.

[88] R.R. Bhosale, R.A. Osmani, B.R. Harkare, P.P. Ghodake, Cubosomes, the inimitable nanoparticulate drug carriers, Scholars Acad. J. Pharm. 2 (2013) 481-486.

[89] P. Kumar, M. Govindaraju, S. Senthamilselvi, K. Premkumar, Photocatalytic degradation of methyl orange dye using silver (Ag) nanoparticles synthesized from Ulva lactuca, Colloids Surf. B Biointerf. 103 (2013) 658-661.

[90] S. Waghmode, P. Chavan, V. Kalyankar, S. Dagade, Synthesis of silver nanoparticles using Triticum aestivum and its effect on peroxide catalytic activity and toxicology, J. Chem. 2013 (2013) 265864:1-6.

[91] K. Muthu, S. Priya, Green synthesis, characterization and catalytic activity of silver nanoparticles using Cassia auriculata flower extract separated fraction, Spectrochim. Acta A Mol. Biomol. Spectrosc. 179 (2017) 66-72.

[92] S.J. Jacob, J.S. Finub, A. Narayanan, Synthesis of silver nanoparticles using Piper longum leaf extracts and its cytotoxic activity against Hep-2 cell line, Colloids Surf. B Biointerf. 91 (2012) 212-214.

[93] F. Baghbani-Arani, R. Movagharnia, A. Sharifian, S. Salehi, S.A. Shandiz, Photocatalytic, anti-bacterial, and anti-cancer properties of phyto-mediated synthesis of silver nanoparticles from Artemisia tournefortiana Rchb extract, J. Photochem. Photobiol. B Biol. 173 (2017) 640-649.

[94] S. Kummara, M.B. Patil, T. Uriah, Synthesis, characterization, biocompatible and anticancer activity of green and chemically synthesized silver nanoparticles-a comparative study, Biomed. Pharmacother. 84 (2016) 10-21.

[95] S. Rajesh Kumar, Anticancer activity of eco-friendly gold nanoparticles against lung and liver cancer cells, J. Genet. Eng. Biotechnol. 14 (2016) 195-202.
[96] D. Zheng, C. Hu, T. Gan, X. Dang, S. Hu, Preparation and application of a novel vanillin sensor based on biosynthesis of $\mathrm{Au}-\mathrm{Ag}$ alloy nanoparticles, Sens. Actuators B Chem. 148 (2010) 247-252.

[97] W.J. Galush, S.A. Shelby, M.J. Mulvihill, A. Tao, P. Yang, J.T. Groves, A nanocube plasmonic sensor for molecular binding on membrane surfaces, Nano Lett. 9 (2009) 2077-2082

[98] A.J. Haes, W.P. Hall, L. Chang, W.L. Klein, R.P. Van Duyne, A localized surface plasmon resonance biosensor, First steps toward an assay for Alzheimer's disease,Nano Lett. 4 (2004) 1029-1034.

[99] F.S. Rosarin, S. Mirunalini, Nobel metallic nanoparticles with novel biomedical properties, J. Bioanal. Biomed. 3 (2011) 85-91.

[100] R. Sarkar, P. Kumbhakar, A.K. Mitra, Green synthesis of silver nanoparticles and its optical properties, Dig. J. Nanomater. Bios. 5 (2010) 491-496.

[101] H. Bao, N. Hao, Y. Yang, D. Zhao, Biosynthesis of biocompatible cadmium telluride quantum dots using yeast cells, Nano Res. 3 (2010) 481-489.

[102] H. Bao, Z. Lu, X. Cui, Y. Qiao, J. Guo, J.M. Anderson, C.M. Li, Extracellular microbial synthesis of biocompatible CdTe quantum dots, Acta Biomater. 6 (2010) 3534 3541.

[103] J.H. Lee, Y.M. Huh, Y.W. Jun, J.W. Seo, J.T. Jang, et al., Artificially engineered magnetic nanoparticles for ultra-sensitive molecular imaging, Nat. Med. 13 (2007) 95-99.

[104] K. Giri, L.R. Yepes, B. Duncan, P.K. Parameswaran, B. Yan, et al., Targeting bacterial biofilms via surface engineering of gold nanoparticles, RSC Adv. 5 (2015) 105551-105559.

[105] S. Taheri, A. Cavallaro, S.N. Christo, L.E. Smith, P. Majewski, et al., Substrate independent silver nanoparticle based antibacterial coatings, Biomater. 35 (2014) 4601-4609.

[106] V. Alt, T. Bechert, P. Steinrücke, M. Wagener, P. Seidel, E. Dingeldein, E. Domann R. Schnettler, An in vitro assessment of the antibacterial properties and cytotoxicity of nanoparticulate silver bone cement, Biomater. 25 (2004) 43834391.

[107] P. Prokopovich, M. Köbrick, E. Brousseau, S. Perni, Potent antimicrobial activity of bone cement encapsulating silver nanoparticles capped with oleic acid, J. Biomed. Mater. Res. B Appl. Biomater. 103 (2015) 273-281.

[108] T. Russo, A. Gloria, R. De Santis, U. D'Amora, G. Balato, et al, Preliminary focus on the mechanical and antibacterial activity of a PMMA-based bone cement loaded with gold nanoparticles, Bioactive Mater. 2 (2017) 156-161.

[109] M. Eskandari Nojehdehi, H. Jafarizadeh Malmiri, J. Rahbar Shahrouzi Optimization of processing parameters in green synthesis of gold nanoparticles using microwave and edible mushroom (Agaricus bisporus) extract and evaluation of their antibacterial activity, Nanotech. Rev. 5 (2016) 537-548.

[110] J. Singh, T. Dutta, Ki-Hyun Kim, M. Rawat, P. Samddar, P. Kumar, Green synthesis of metals and their oxide nanoparticles: applications for environmental remediation, J. Nanobiotech. 16(84) (2018) 1-24.

[111] B. Kumar, K. Smita, L. Cumbal, A. Debut, Green synthesis of silver nanoparticles using Andean blackberry fruit extract, Saudi J. Bio. Sci. 24 (2017) 45-50.

[112] V. Armendariz, I. Herrera, M. Jose-yacaman, H. Troiani, P. Santiago, J.L. GardeaTorresdey, Size controlled gold nanoparticle formation by Avena sativa biomass: use of plants in nanobiotechnology, J. Nano. Res. 6 (2004) 377-382.

[113] S.S. Shankar, A. Rai, A. Ahmad, M. Sastry, Rapid synthesis of Au, Ag, and bimetallic Au core-Ag shell nanoparticles using Neem (Azadirachta indica) leaf broth, J. Colloid Interf. Sci. 275 (2004) 496-502.

[114] N.A. Begum, S. Mondal, S. Basu, R.A. Laskar, D. Mandal, Biogenic synthesis of Au and Ag nanoparticles using aqueous solutions of black tea leaf extracts, Colloids Surf. B: Biointerf. 71 (2009) 113-118.

[115] R.G. Haverkamp, A.T. Marshall, The mechanism of metal nanoparticle formation in plants: limits on accumulation, J. Nano Res. 11 (2009) 1453-1463.

[116] N.C. Sharma, S.V. Sahi, S. Nath, J.G. Parsons, J.L. Gardea-Torresde, T. Pal, Synthesis of plant-mediated gold nanoparticles and catalytic role of biomatrixembedded nanomaterials, Environ. Sci. Tech. 41 (2007) 5137-5142.

[117] N. Mude, A. Ingle, A. Gade, M. Rai, Synthesis of silver nanoparticles using callus extract of Carica papaya-a first report, J. Plant. Biochem. Biotech. 18 (2009) 83 86.

[118] T.C. Prathna, N. Chandrasekaran, A.M. Raichur, A. Mukherjee, Biomimetic synthesis of silver nanoparticles by Citrus limon (lemon) aqueous extract and theoretical prediction of particle size, Colloid. Surf. B: Bio. 82 (2011) 152-159.

[119] K.B. Narayanan, N. Sakthivel, Coriander leaf mediated biosynthesis of gold nanoparticles, Mater. Lett. 62 (2008) 4588-4590.

[120] M. Dubey, S. Bhadauria, B.S. Kushwah, Green synthesis of nanosilver particles from extract of Eucalyptus hybrida (safeda) leaf, Dig. J. Nanomater. Biostruct. 4 (2009) 537-543.

[121] S. Ravindra, Y.M. Mohan, N.N. Reddy, K.M. Raju, Fabrication of antibacterial cotton fibres loaded with silver nanoparticles via "Green Approach", Colloid Surf. A 367 (2010) 31-40.

[122] R. Veerasamy, T.Z. Xin, S. Gunasagaran, T.F. Xiang, E.F. Yang, N. Jeyakumar, S.A Dhanaraj, Biosynthesis of silver nanoparticles using mango steen leaf extract and evaluation of their antimicrobial activities, J. Saudi. Chem. Soc. 15 (2010) 113-120.

[123] D. Philip, Honey mediated green synthesis of gold nanoparticles, Spectrochim. Acta A Mol. Biomol. Spectrosc. 73 (2009) 650-653.

[124] D. Raghunandan, M.D. Bedre, S. Basavaraja, B. Sawle, S.Y. Manjunath, A Venkataraman, Rapid biosynthesis of irregular shaped gold nanoparticles from macerated aqueous extracellular dried clove buds (Syzygium aromaticum) solution, Colloid Surf. B Biointerf. 79 (2010) 235-240.

[125] P.S. Schabes-Retchkiman, G. Canizal, R. Herrera-Becerra, C. Zorrilla, H.B. Liu, J.A Ascencio, Biosynthesis and characterization of Ti/Ni bimetallic nanoparticles, Optical Mater. 29 (2006) 95-99.

[126] D. Mubarak Ali, N. Thajuddin, K. Jeganathan, M. Gunasekaran, Plant extract mediated synthesis of silver and gold nanoparticles and its antibacterial 
activity against clinically isolated pathogens, Colloids Surf. B: Biointerf. 85 (2011) 360-365.

[127] A. Narayanamma, A. Rani, M.E. Raju, Natural synthesis of silver nanoparticles by banana peel extract and as an antibacterial agent, Int. J. Sci. Res. 5 (2016) 1431-1441.

[128] T. Santhoshkumar, A.A. Rahuman, G. Rajakumar, S. Marimuthu, A. Bagavan, et al., Synthesis of silver nanoparticles using Nelumbo nucifera leaf extract and its larvicidal activity against malaria and filariasis vectors, Parasitology Res. 108 (2011) 693-702.

[129] D. Philip, C. Unni, Extracellular biosynthesis of gold and silver nanoparticles using Krishna tulsi (Ocimum sanctum) leaf, Physica. E. Low Dimens. Syst. Nanostruct. 43 (2011) 1318-22.

[130] M.M. Khalil, E.H. Ismail, K.Z. El-Baghdady, D. Mohamed, Green synthesis of silver nanoparticles using olive leaf extract and its antibacterial activity, Arab. J. Chem. 7 (2014) 1131-1139.
[131] S.S. Shankar, A. Ahmad, R. Pasricha, M. Sastry, Bioreduction of chloroaurate ions by geranium leaves and its endophytic fungus yields gold nanoparticles of different shapes, J. Mater. Chem. 13 (2003) 1822-1826.

[132] I.K. Sen, A.K. Mandal, S. Chakraborti, B. Dey, R. Chakraborty, S.S. Islam, Green synthesis of silver nanoparticles using glucan from mushroom and study of antibacterial activity, Int. J. Biol. Macromol. 62 (2013) 439-449.

[133] D. Raghunandan, S. Basavaraja, B. Mahesh, S. Balaji, S.Y. Manjunath, A. Venkataraman, Biosynthesis of stable polyshaped gold nanoparticles from microwave-exposed aqueous extracellular anti-malignant guava (Psidium guajava) leaf extract, Nanobiotechnol. 5 (2009) 34-41.

[134] V. Kumar, S.C. Yadav, S.K. Yadav, Syzygium cumini leaf and seed extract mediated biosynthesis of silver nanoparticles and their characterization, J. Chem. Technol. Biotech. 85 (2010) 1301-1309. 